\title{
Macrophage Inflammatory Protein Type 1 Beta as a Novel Diagnostic Marker for Diagnosis of Spontaneous Bacterial Peritonitis
}

\author{
Alaa N Mahmoud ${ }^{1}$, Sahar El-gharabawy ${ }^{1}$, Rania Elhelaly ${ }^{2}$, Maha R. Habeeb ${ }^{1, *}$ \\ ${ }^{1}$ Internal Medicine Department, Faculty of medicine, Mansoura University, Mansoura, Egypt; ${ }^{2}$ Clinical pathology department, \\ Faculty of medicine, Mansoura University, Mansoura, Egypt.
}

\begin{abstract}
Background: Spontaneous bacterial peritonitis (SBP) is a severe complication of cirrhotic ascites. SBP diagnosis is based on the count of ascitic fluid neutrophils $\left(>250 / \mathrm{mm}^{3}\right)$. This procedure is an invasive maneuver with many complications. This study aimed to find a sensitive diagnostic tool for SBP by examining ascitic fluid Macrophage Inflammatory Protein type 1 beta (MIP-1 $\beta$ ) as a rapid bedside test for diagnosis of SBP. Materials and methods: The study included 53 cirrhotic ascitic patients (33 with and 20 without SBP). Patients were subjected to thorough medical history taking, clinical examination, and laboratory investigation. Two ascitic fluid samples were taken, the first at admission time for cell count and culture, and the second sample was taken 48 hours after treatment in patients with SBP. Ascitic MIP-1 $\beta$ was measured using ELISA technique at admission in both groups and 48 hours after treatment in the SBP group. Results: Ascitic MIP-1 $\beta$ and CRP levels were significantly higher in the SBP group versus non-SBP patients. There was a significant positive correlation between ascitic fluid MIP-1 $\beta$ and WBCs and serum CRP. Ascitic fluid MIP-1 $\beta$ at a cut-off value $\geq$ of $31.95 \mathrm{pg} / \mathrm{ml}$ had $79 \%$ sensitivity and $75 \%$ specificity for the diagnosis of SBP. Combined ascetic fluid MIP-1 $\beta$ at the cut-off value $\geq 31.95 \mathrm{pg} / \mathrm{ml}$ and CRP in serum at a cut-off value $\geq$ of $36 \mathrm{mg} / \mathrm{L}$ had $61 \%$ sensitivity and $100 \%$ specificity. There was a significant decrease of both, ascitic MIP-1 $\beta$ and ascetic fluid PMN after treatment of SBP. Conclusions: Ascitic fluid MIP-1 $\beta$ is highly sensitive and specific in the diagnosis of SBP- especially when combined with CRP.
\end{abstract}

\section{Introduction}

Cirrhotic patients with ascites are immunocompromised with higher susceptibility to infections such as SBP, hospital-acquired infections, and a variety of other infections from uncommon pathogens, mainly owing to the inadequate innate and specific defense mechanisms ${ }^{1}$. SBP is defined as an ascitic fluid PMN $>250 / \mathrm{mm}^{3}$ after exclusion of intraabdominal surgically-treatable source ${ }^{2}$. SBP is a potential, life-threatening complication in cirrhotic patients

Keywords: Spontaneous bacterial peritonitis, macrophage inflammatory protein type 1 beta, cirrhosis, ascites

Received: 26-12-2020; Accepted: 23-2-2021

* Corresponding author. Email: maha_ragab68@ hotmail.com with a mortality rate ranging between $30 \%$ and $50 \%{ }^{3}$. Early diagnosis and appropriate treatment can reduce morbidity and mortality in SBP patients ${ }^{1}$. SBP may be symptomatic, therefore all cirrhotic patients with ascites should undergo diagnostic paracentesis at admission to diagnose SBP whatever the cause of admission, although SBP is less common in an outpatient setting, it is necessary to evaluate it especially in patients on the waiting list for liver transplantation because of high mortality ${ }^{4}$. Ascitic fluid PMN $>250 / \mathrm{mm}^{3}$ can diagnose SBP in absence of intraabdominal surgical and inflammatory causes of secondary peritonitis ${ }^{5}$. Macrophage inflammatory protein type 1 beta (MIP-1 $\beta$ ) belongs to the family of chemokines, best known for their chemotactic and proinflammatory effects. Synthesis of MIP-1p is stimulated by bacterial endotoxins. MIP-1 $\beta$ is responsible for the activation of PMN and is part of acute neutrophilic inflammation. The diagnostic importance of MIP-1 $\beta$ for bacterial infections is poorly recognized. The chemokines have significantly shorter halflives than classical inflammatory biomarkers which theoretically make them more suitable for diagnostic and monitoring purposes ${ }^{6}$. The present study aims to assess the role of ascitic fluid MIP-1 $\beta$ as an early detector for the diagnosis of SBP and follow-up of these patients.

\section{Patients and methods}

This is a prospective case-control study that included 53 cirrhotic patients with ascites. The patients were classified into two groups; Group (1) included 33 patients with ascitic fluid PMN > 250/ $\mathrm{mm}^{3}$ (SBP group), and group (2) included 20 patients with an ascitic neutrophil count below 250 cells $/ \mathrm{mm}^{3}$ and -ve culture (Non-SBP group). Our patients were admitted to Specialized Medical Hospital, Mansoura University from January 2016 till the end of January 2017. All patients were above 18 years. Patients who had hepatocellular carcinoma, extrahepatic malignancy, recent abdominal surgery, hemoperitoneum, recent antibiotic therapy (within 48 hours before admission) chronic dialysis, acute pancreatitis, autoimmune diseases, organ transplant, HIV infections, or having other infections were excluded from the study. All patients underwent a thorough clinical evaluation (history taking, general and systemic examination). Laboratory tests, including complete CBC, serum creatinine, liver function tests, serum CRP, and urine analysis, radiological investigations (abdominal ultrasound, chest-X ray, and Triphasic CT when indicated) were done. Ascitic fluid analysis and culture were done at index 
admission in both groups and 48 hours after treatment in the SBP group.

\section{Ascitic fluid MIP-1及}

Ascitic fluid MIP-1 $\beta$ was measured by ELISA kit supplied by Sun RED (China). The unit utilizes a twofold counteracting agent sandwich catalyst connected immunosorbent examine (ELISA) to test the level of Human Macrophage Inflammatory Protein-1 $\beta$ (MIP-1 $\beta$ ) in tests. Include MIP-1 $\beta$ to monoclonal counter acting agent Enzyme well which is precoated with MIP-1 $\beta$ monoclonal neutralizer, hatching; at that point, include (MIP-1 $\beta$ ) antibodies marked with biotin, and joined with Streptavidin-HRP to shape resistant complex; at that point do brooding and washing again to evacuate the uncombined compound. At that point include Chromogen Solution A, B, the shade of the fluid changes into the blue, and at the impact of corrosive, the shading at last winds up yellow. The Chroma of shading and the grouping of the MIP- $1 \beta$ for example were decidedly connected. The sensitivity of this assay is defined as the lowest protein concentration which can be differentiated from zero. It was determined by subtracing two standard deviations to the mean optical density value of twenty zero standard replicates and calculating the corresponding concentration. This was estimated to be $0.432 \mathrm{pg} / \mathrm{ml}$. Moreover, assay range was between $0.5 \mathrm{pg} / \mathrm{ml}$ and $150 \mathrm{pg} / \mathrm{ml}$. The mean absorbance for each set of duplicate standards, controls, and samples was calculated. The average zero standard optical density was subtracted. The standard curve on log-log graph paper was the plot. The standard concentration was on the $\mathrm{x}$-axis and absorbance was on the $y$-axis. The best-fit straight line through the standard points was drawn.

\section{Statistical analysis}

Correlation analysis between continuous data and ascitic fluid MIP-1 $\beta$ was done using the Spearman correlation test. Correlation between Categorical data and ascitic fluid MIP$1 \beta$ was done using the Bi-seial correlation test. Association between potential predictors of SBP with SBP was done using logistic regression analyses. Comparison between different regressions models was done by -2 Log-likelihood (-2LL). The ability of ascitic fluid MIP-1 $\beta$ to discriminate between individuals with and without SBP was determined by the ROC curve. The best cutoff point was chosen according to Youden's index. Change of ascitic fluid PMN and MIP-1 $\beta$ before and after treatment determined by Wilcoxon signed-rank test.

\section{Results}

There was no significant difference between the two studied groups as regards, age, gender, gastrointestinal bleeding, hepatic encephalopathy serum creatinine, and albumin and hemoglobin level. Compared to patients without SBP, patients with SBP showed a significant increase as regards, fever, abdominal pain, serum bilirubin, INR, Child C score, and MELD score, and a significant decrease in platelet count as shown in (Table 1).

Furthermore, there was a significant increase as regards, ascitic MIP-1 $\beta$, ascitic fluid PMN, ascitic LDH and serum CRP levels, and peripheral WBC in the SBP group versus the non- SBP group as shown in (Table 2).

There was a significant correlation between ascetic MIP-1 $\beta$ and peripheral WBCs, ascitic fluid LDH, and CRP level while, no statistically significant correlation between MIP-1 $\beta$ and other studied parameters (Table 3). To determine predictive parameters for the diagnosis of SBP, variables with significant associations on Univariate analysis were subjected to logistic regression analysis.

The multiple logistic regression analyses of predictors of SBP were illustrated in (Table 4). The presence of abdominal pain, fever and increase WBCs, serum CRP level, ascetic MIP-1 $\beta$, Child-Pugh score, and MELD score were independent predictor factors for SBP.

(Table 5) shows that ascitic fluid MIP-1 $\beta$ at a cut-off value $\geq$ of 31.95 can discriminate individuals with SBP from those without SBP with sensitivity (79\%) and specificity (75\%), NPV (84\%), PPV (68\%) accuracy $(77 \%)$. Also, CRP in serum at a cut-off value $\geq$ of $36 \mathrm{mg} / \mathrm{L}$ can distinguish individuals with SBP from those without SBP with sensitivity (73\%) and specificity (95\%), NPV $(68 \%)$, PPV (96\%) accuracy (81\%). The addition of CRP in serum at a cut-off value $\geq$ of $36 \mathrm{mg} / \mathrm{L}$ to ascetic fluid MIP-1 $\beta$ at a cut-off value $\geq$ of $31.95 \mathrm{pg} / \mathrm{ml}$ increased specificity to $(100 \%)$ with $61 \%$ sensitivity

Table 1. Demographic, clinical, and laboratory parameters of the studied groups.

\begin{tabular}{|c|c|c|c|}
\hline Characteristics & SBP $(N=33)$ & Non-SBP $(\mathbf{N}=20)$ & P-value \\
\hline Age (years) $($ mean \pm SD $)$ & $58.8 \pm 8.9$ & $50.7 \pm 10.1$ & 0.683 \\
\hline \multicolumn{4}{|l|}{ Gender (\%) } \\
\hline Male & $16(48.5 \%)$ & $7(35.0 \%)$ & 0.337 \\
\hline Female & $17(51.5 \%)$ & $13(65.0 \%)$ & \\
\hline \multicolumn{4}{|l|}{ Abdominal pain (\%) } \\
\hline Yes & $28(84.8 \%)$ & $8(40 \%)$ & 0.001 \\
\hline No & $5(15.2 \%)$ & $12(60 \%)$ & \\
\hline \multicolumn{4}{|l|}{ Fever $(\%)$} \\
\hline Yes & $19(57.6 \%)$ & $4(20 \%)$ & 0.010 \\
\hline No & $14(42.4 \%)$ & $16(80 \%)$ & \\
\hline
\end{tabular}




\begin{tabular}{|c|c|c|c|}
\hline $\begin{array}{l}\text { Hepatic encephalopathy } \\
\text { Yes } \\
\text { No }\end{array}$ & $\begin{array}{c}8(24.2 \%) \\
25(75.8 \%)\end{array}$ & $\begin{array}{c}3(15 \%) \\
17(85 \%)\end{array}$ & 1.000 \\
\hline GIT bleeding (\%) & & & \\
\hline $\begin{array}{l}\text { Yes } \\
\text { No }\end{array}$ & $\begin{array}{c}7(21.2 \%) \\
26(78.8 \%)\end{array}$ & $\begin{array}{c}1(5 \%) \\
19(95 \%)\end{array}$ & 1.000 \\
\hline Serum Bilirubin (mg/dl) & $3.8(1.75-7.2)$ & $1.5(0.7-2.9)$ & 0.002 \\
\hline Serum creatinine (mg/dl) & $1.5(0.9-2.3)$ & $1.1(1.0-1.6)$ & 0.185 \\
\hline Serum albumin $(\mathrm{gm} / \mathrm{dl})($ mean \pm SD $)$ & $2.3 \pm 0.5$ & $2.5 \pm 0.5$ & 0.474 \\
\hline INR $($ mean \pm SD) & $1.9 \pm 0.5$ & $1.4 \pm 0.4$ & 0.003 \\
\hline Platelets $\left(10^{3} / \mathrm{mm}^{3}\right)$ & $64.0(51.0-121.5)$ & $114(65.3-152.3)$ & 0.033 \\
\hline Hemoglobin $($ gm/dl) $($ mean \pm SD $)$ & $10.3 \pm 2.1$ & $11.0 \pm 2.4$ & 0.265 \\
\hline Child-Pugh classification & $11.0(9.0-12.0)$ & $9.0(8.0-10.0)$ & \\
\hline Child A & $2(6.1 \%)$ & $2(10 \%)$ & 0.002 \\
\hline Child B & $6(18.2 \%)$ & $13(65 \%)$ & \\
\hline Child C & $25(75.7 \%)$ & $5(25 \%)$ & \\
\hline MELD score & $21.0(17.5-29.5)$ & $12.5(10.0-17.5)$ & $<0.001$ \\
\hline
\end{tabular}

MELD Score, Model for end-stage liver disease

Table 2. Comparison of MIP-1ß, and other inflammatory markers between the studied groups.

\begin{tabular}{|c|c|c|c|}
\hline Characteristics & SBP $(\mathbf{N}=33)$ & Non-SBP $(\mathbf{N}=20)$ & P-Value \\
\hline Ascitic fluid MIP-1ß (pg/ml) & $44.1(33.2-47.8)$ & $18.4(14.7-40.4)$ & 0.002 \\
\hline Ascitic fluid PMN $\left(10^{3} / \mathrm{mm}^{3}\right)$ & $2700(1127-5864)$ & $200.0(102.0-250.0)$ & $<0.001$ \\
\hline Ascitic fluid LDH (IU/L) & $160.0(117.0-208.5)$ & $86.0(72.8-118.0)$ & $<0.001$ \\
\hline Serum CRP level (mg/dl) & $72.0(12.0-96.0)$ & $24.0(12.0-24.0)$ & 0.002 \\
\hline Peripheral WBCs $\left(\times 10^{3} / \mathrm{mm}^{3}\right)$ & $8.7(6.2-12.8)$ & $5.9(3.5-7.1)$ & 0.003 \\
\hline
\end{tabular}

Table 3: Correlation between ascitic MIP-1 and Biochemical characteristics, MELD and Child-Pugh classification.

\begin{tabular}{|c|c|c|}
\hline Variable & $\mathbf{r}$ & P-Value \\
\hline Serum Creatinine (mg/dl) & 0.143 & 0.307 \\
\hline Serum Albumin (gm/dl) & -0.042 & 0.766 \\
\hline Serum Bilirubin (mg/dl) & 0.015 & 0.914 \\
\hline INR & 0.207 & 0.136 \\
\hline Platelet $\left(10^{3} / \mathrm{mm}^{3}\right)$ & 0.89 & 0.525 \\
\hline WBC $\left(10^{3} / \mathrm{mm}^{3}\right)$ & 0.443 & $0.001 *$ \\
\hline Ascitic fluid neutrophils $\left(10^{3} / \mathrm{mm}^{3}\right)$ & 0.198 & 0.270 \\
\hline Ascitic fluid glucose (mg/dl) & -0.036 & 0.800 \\
\hline Ascitic fluid albumin (gm/dl) & 0.060 & 0.671 \\
\hline Ascitic fluid LDH (mg/dl) & 0.312 & $0.023 *$ \\
\hline Serum CRP concentration (mg/L) & 0.131 & $0.007 *$ \\
\hline MELD score & 0.212 & 0.128 \\
\hline Child-Pugh classification & 0.171 & 0.222 \\
\hline
\end{tabular}

Table 4: Prediction of SBP by Clinical and laboratory predictors of SBP.

\begin{tabular}{|c|c|c|c|}
\hline Variable & OR $(95 \% \mathrm{Cl})$ & $-2 L L$ & P-Value \\
\hline Fever (YES) & $5.42(1.49-19.82)$ & 62.7 & 0.010 \\
\hline Abdominal pain (YES) & $8.4(2.28-31.01)$ & 58.7 & 0.001 \\
\hline WBC $\left(10^{3} / \mathrm{mm}^{3}\right)$ & $1.34(1.08-1.69)$ & 59.1 & 0.009 \\
\hline Serum CRP level (mg/L) & $5.65(1.91-16.78)$ & 52.8 & 0.002 \\
\hline Ascitic fluid MIP- $\beta(\mathrm{pg} / \mathrm{ml})$ & $1.075(1.03-1.12)$ & 56.8 & 0.001 \\
\hline Child-Pugh Score & $1.54(1.11-2.14)$ & 61.8 & 0.008 \\
\hline MELD Score & $1.25(1.08-1.42)$ & 51.9 & 0.001 \\
\hline
\end{tabular}




\begin{tabular}{|c|c|c|c|c|c|c|c|}
\hline Variable & Cut off point & AUC (95-CI) & Sensitivity & Specificity & NPV & PPV & Accuracy \\
\hline $\begin{array}{l}\text { Ascetic fluid MIP- } \\
\qquad \beta\end{array}$ & $\geq 31.95 \mathrm{pg} / \mathrm{ml}$ & $0.76(0.61-0.90)$ & $79 \%$ & $75 \%$ & $84 \%$ & $68 \%$ & $77 \%$ \\
\hline Serum CRP & $\geq 36 \mathrm{mg} / \mathrm{L}$ & 0.89 & $73 \%$ & $95 \%$ & $68 \%$ & $96 \%$ & $81 \%$ \\
\hline $\begin{array}{c}\text { Combined ascetic } \\
\text { fluid MIP-1 } \beta \text { and } \\
\text { serum CRP }\end{array}$ & & & $61 \%$ & $100 \%$ & $61 \%$ & $100 \%$ & $75 \%$ \\
\hline
\end{tabular}

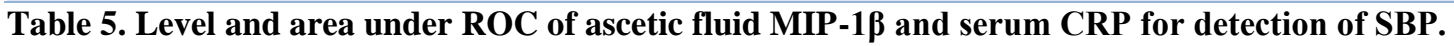

\section{Discussion}

SBP is a serious cause of morbidity as well as mortality in patients with cirrhosis and ascites. Diagnosis of SBP should be early and accurate to avoid its complications ${ }^{7}$. The diagnosis of SBP is mainly dependent on a manual count of the ascitic fluid count of PMN which, is operatordependent and the false-negative result may occur due to destruction of PMN during transport. Furthermore, ascitic fluid culture is positive nearly in $30 \%$ of SBP patients and time consuming, so searching for a more sensitive diagnostic tool for SBP is needed ${ }^{8}$. MIP- $1 \beta$ known also as CCL4 is an active protein, which is produced by macrophages. MIP-1 $\beta$ acts as a mitogen- inducible cytokine which stimulates inflammatory responses ${ }^{7}$. In the present study, ascitic fluid MIP-1 $\beta$ was statistically significantly higher in the SBP group in comparison to non-SBP ascitic cirrhotic patients. This result is following previous studies that demonstrated that, increasing ascitic MIP-1 $\beta$ inpatients with SBP 6,7,9-11. We also found that, at cut-off value $\geq 31.95 \mathrm{pg} / \mathrm{ml}$, ascitic fluid MIP-1 $\beta$ had $79 \%$ sensitivity and $75 \%$ specificity to detect SBP with a positive predictive value $(68 \%)$ and negative predictive value $(84 \%)$. Lesinska et al found that, at cut-off value $69.4 \mathrm{pg} / \mathrm{ml}$, MIP- $1 \beta$ had $80 \%$ sensitivity and $72.7 \%$ specificity for prediction of SBP with PPV (57.1\%) and N PV (88.9\%) 6. Another study reported that, ascitic fluid MIP-1 $\beta$ with cut off value 121.9 $\mathrm{pg} / \mathrm{ml}$ (76.1\% sensitivity, $100 \%$ specificity, PPV $100 \%$ and NPV $80 \%$, AUC $=0.881)^{7}$. As regards acute inflammatory marker $\mathrm{C}$ reactive protein (CRP) in serum, the current study showed a significant increase in SBP versus none SBP group. This result matched with previous results ${ }^{7,9,12-15}$.

In this study, we also found that, at cut-off value $\geq 36$ $\mathrm{mg} / \mathrm{L}, \mathrm{CRP}$ had a sensitivity of $73 \%$ and a specificity of $95 \%$ with PPV 96\%, NPV 68\%, and accuracy $81 \%$ for the diagnosis of SBP with AUC 0.89. Previous studies demonstrated that CRP has a diagnostic value in SBP where is CRP at a cut-off value of $30 \mathrm{mg} / \mathrm{L}$ had a sensitivity of 90\% and specificity $96 \%$ with PPV $70 \%$ and NPV $95 \%$ ( AUC $=0.91)^{12}$. Mousa et al found that CRP $>11.3 \mathrm{mg} / \mathrm{dL}$ had a sensitivity of $88.9 \%$ and specificity $92.6 \%{ }^{16}$. Interestingly, in the current study combination of serum $\mathrm{CRP}$ at the cut-off value $\geq$ of $36 \mathrm{mg} / \mathrm{L}$ and ascitic fluid MIP$1 \beta$ at the cut-off value $\geq$ of $31.95 \mathrm{pg} / \mathrm{ml}$ increase specificity up to $100 \%$, however, sensitivity was $61 \%$. The present study showed that both CRP and ascitic fluid MIP-1 $\beta$ were strong independent predictors of SBP. Another study found that CRP was an independent variable in SBP prediction ${ }^{12,16}$ while others found that CRP act as a prognostic marker in cases of cirrhotic ascites with SBP ${ }^{9,14}$. In this study, there was a positive correlation with total leucocyte count, serum CRP and ascitic fluid LDH in the SBP group. However, Khorshed et al found a positive correlation between MIP$1 \beta$, mean platelet volume, platelet distribution width, and PMN in ascites ${ }^{7}$. The current study revealed a significant decrease in ascitic fluid MIP-1 $\beta$ after 48 hours of proper intravenous antibiotic administration. A similar result was reported by El-Gindy et al, who found a significant decrease in MIP-1 $\beta$ in the ascitic fluid after MIP- $1 \beta^{17}$.

\section{Conclusion}

Ascitic fluid MIP-1 $\beta$ is a highly sensitive and specific marker in the diagnosis of SBP- especially when combined with CRP.

\section{References}

1. Bunchorntavakul, C., Chamroonkul, N., and Chavalitdhamrong., D. (2016). Bacterial infections in cirrhosis: a critical review and practical guidance. World journal of hepatology, 8(6), 307.

2. Orman, E. S., Hayashi, P. H., Bataller, R., et al. (2014). Paracentesis is associated with reduced mortality in patients hospitalized with cirrhosis and ascites. Clinical Gastroenterology and Hepatology, 12(3), 496-503. e491.

3. Thévenot, T., Cadranel, J. F., Nguyen-Khac, E., et al. (2004). Diagnosis of spontaneous bacterial peritonitis in cirrhotic patients by use of two reagent strips. European journal of gastroenterology \& hepatology, 16(6), 579-583.

4. Rimola, A., García-Tsao, G., Navasa, M., et al. (2000). Diagnosis, treatment and prophylaxis of spontaneous bacterial peritonitis: a consensus document. Journal of hepatology, 32(1), 142-153.

5. Liver, E. A. F. T. S. O. T. (2010). EASL clinical practice guidelines on the management of ascites, spontaneous bacterial peritonitis, and hepatorenal syndrome in cirrhosis. Journal of Hepatology, 53(3), 397-417.

6. Lesińska, M., Hartleb, M., Gutkowski, K., et al. (2014). Procalcitonin and macrophage inflammatory protein-1 beta (MIP-1 $\beta$ ) in serum and peritoneal fluid of patients with decompensated cirrhosis and spontaneous 
bacterial peritonitis. Advances in medical sciences, 59(1), 52-56.

7. Khorshed, S. E., Ibraheem, H. A., and Awad, S. M. (2015). Macrophage Inflammatory Protein-1 Beta (MIP-1 $\beta$ ) and Platelet Indices as Predictors of Spontaneous Bacterial Peritonitis-MIP, MPV and PDW in SBP.Open Journal of Gastroenterology, 5(07), 94.

8. Soriano, G., Esparcia, O., Montemayor, M., et al. (2011). Bacterial DNA in the diagnosis of spontaneous bacterial peritonitis. Alimentary pharmacology \& therapeutics, 33(2), 275-284.

9. Shizuma, T. (2016) .Diagnostic Laboratory Markers for Spontaneous Bacterial Peritonitis. Annals of clinical and Laboratory Research Vol 4 NO 4:131.

10. Pepys, M. B., and Hirschfield, G. M. (2003). C-reactive protein: a critical update. The Journal of clinical investigation, 111(12), 1805-1812.

11. Suvak, B., Torun, S., Yildiz, H., et al. (2015). Mean platelet volume is a useful indicator of systemic inflammation in cirrhotic patients with ascitic fluid infection. Annals of hepatology, 12(2), 294-300.

12. Rizk, E., Elzehery, R., Zakaria, S., et al. (2014). Ascitic fluid calprotectin and serum C-reactive protein as diagnostic markers for spontaneous bacterial peritonitis. Afro-Egyptian Journal of Infectious and Endemic Diseases, 4(3), 117-125.

13. Kalvandi, G., Honar, N., Geramizadeh, B., et al. (2016). Serum C-reactive protein in children with liver disease and ascites. Hepatitis monthly, 16(8).

14. Galal, G.M.K., Elsharkawy, R.M., Said, S. A., et al. (2019). Predictors of Ascitic Fluid Infection in Cirrhotic Patients .Sohag Medical Journal Vol. 23 No. 1

15. Elsadek, H. M., Elhawari, S. A., and Mokhtar, A. (2020). A novel serum index for accurate diagnosis of spontaneous bacterial peritonitis in cirrhotic patients without other infections. Egyptian Liver Journal, 10(1), 1-8.

16. Mousa, N., Besheer, T., Abdel-Razik, A., et al. (2018). Can combined blood neutrophil to lymphocyte ratio and C-reactive protein be used for diagnosis of spontaneous bacterial peritonitis? British journal of biomedical science, 75(2), 71-75.

17. El-Gindy, E. M., Abd El-Kader, N. A., Montasser, I. F., et al. (2018). Evaluation of macrophage inflammatory protein-1 $\beta$ in diagnosis of spontaneous bacterial peritonitis. Egyptian Liver Journal, 8(3), 93-97. 